\title{
Pluralismo, Estado de Derecho y Derechos Humanos
}

Uno de los elementos esenciales de la comprensión europea del derecho es el de pensar que la idea del derecho se funda en la razón, ya sea en un concepto metafísico de razón o sea -dicho pragmáticamente- en la racionalidad de lo racional. Por razón se entiende la capacidad humana del autodominio y de la configuración de la realidad de acuerdo con la mesura de lo humano. El concepto sustancial de una razón existente independientemente de los hombres, ya no forma parte, sin embargo de la autocomprensión de la cultura europea. Los intereses y las actitudes, las experiencias y las imágenes del mundo de los "racionales" (como individuos concretos) se han pluralizado en la sociedad civil moderna.

El estado de derecho, los derechos fundamentales y los derechos humanos son una respuesta, en el marco de las condiciones del pluralismo fáctico, a la cuestión de cómo puede levantarse un mundo más justo a partir de la libertad todavía encadenada de los hombres.

No voy a hablar en un sentido general sobre los derechos humanos sino que lo haré desde una perspectiva limitada y determinada. Mi cuestión es esta: ¿Cuáles son los contextos esenciales de la validez de los derechos humanos? ¿Se puede hablar de los derechos humanos silenciando el derecho y el estado? Y mi respuesta va a ser ésta: Por más allá de la necesidad de una teoría general y de una política concreta de los derechos humanos -que no cuestiono-, éstos tienen que ser objeto del desarrollo del derecho a los derechos humanos. Esto significa ante todo: 1 . Reflexionar sobre la relación entre derecho y estado; y 2. Tomar mayor conciencia de que, hoy y por largo tiempo, los lugares para hacer respetar los derechos humanos son el estado y las instituciones jurídicas interestatales. Esto significa sin embargo comprender también que, por el derecho procedente de la soberanía de los pueblos y vigente en los estados, material- 
mente no está vinculado a ningún modelo universal en razón de los diferentes ideales de la justicia y de las distintas tradiciones jurídicas. Esto vale, por ejemplo, para el derecho de propiedad y para las formas de la obligación social de la propiedad, es decir, para las alternativas de la mancomunidad. Parto en mi argumentación de un diagnóstico que se caracteriza como "pluralismo fáctico", para preguntar luego por el sentido y los límites de la crítica al estado y para esclarecer las mutuas relaciones entre derecho y estado. Abogaré además a favor del principio de la legitimación de todas las funciones estatales en un estado democrático de derecho desde la justicia social y política, es decir, de la justificación del estado mediante funciones jurídicas y sociales. En este contexto hablo a favor de una complementariedad entre positivismo jurídico e ideas iusnaturalistas regulativas.

Finalmente haré un balance: El derecho a los derechos humanos determina hoy la universalidad y reciprocidad de la concesión de derechos fundamentales entre ciudadano.

\section{El 'pluralismo fáctico'}

El pluralismo sienta sus bases esenciales, pero también sus limites, en la participación de los individuos en el saber, en los grados de su capacidad de juicio y en sus convicciones. Los ideales individuales y colectivos, los fines propuestos, las normas jurídicas y las metas del estado representan también "contenidos de sentido" y "esquemas de interpretación" (H. Kelsen) que forman parte de un contexto cultural. Hacen referencia a la historia y pertenecen al "sentido propio" (obstinado) de una cultura. Esto tiene consecuencias también para la comprensión de la democracia, esto es, del orden de la justicia social y política: los debates sobre la definición de la democracia son parte integrante de situaciones históricas, y ninguna definición tiene un monopolio de la verdad. Sóto una "definición mínima", —como por ejemplo la propuesta por N. Bobbio, puede reclamar ser vinculante: La democracia "debe ser entendida como un conjunto de reglas (primarias o fundamentales) que fijan quién tiene derecho a participar en las decisiones colectivas y con qué procedimiento se van a tomar esas decisiones."

Las ideas y normas jurídicas derivadas de las exigencias de los derechos fundamentales y de los derechos humanos están hipotecadas con el problema de que su normatividad depende de su grado de contacto con la realidad, es decir, que tienen que realizar la universalidad de su validez bajo las condiciones de la particularidad y pluralidad de las formas de pensar y de comportamiento de los destinatarios de la norma. Es parte de la situación del pluralismo fáctico" que los principios formulados en la modernidad sobre la "participación en la formación de la voluntad política, el respecto igual a los intereses de todos los miembros y... la propia responsabilidad del juicio moral no bastan para la "garantía dura- 
dera de la libertad": "la preservación del juicio ético-moral individual puede quizás favorecer un clima de tolerancia liberal, pero no defiende contra reglas aprobadas mayoritariamente que obligan a otro comportamiento". De facto los principios, que son constitutivos de una sociedad pluralista, son cuestionables. Eso vale también para el principio "la dignidad del hombre es inviolable". Los intentos de estabilizar este principio como un "valor objetivo" interpretándolo como un sucedáneo laicista de la fundamentación del derecho fundamental a partir de "Dios como (el) fundamento de todo lo creado", son intentos condenados al fracaso. El "derecho natural de cuño moderno" es mucho más que una simple traducción de la "concepción cristiana del derecho natural".

No obstante las sociedades pluralistas tienen también el problema de que los hombres —quieran o no- están obligados "a conservar la integridad de su convivencia orientándose en los principios de la justicia y respetándose entre sí y como miembros de una asociación de seres e iguales". Pero, ¿cómo alcanzamos la "integridad de una cultura jurídica" que es irrenunciable incluso en condiciones pluralistas?. La cultura jurídica "consiste en que resoluciones constitucionales, leyes y decisiones particulares, que se tienen por buenas, deben poder ser armonizadas con principios y metas generales".

No podemos por eso quedarnos en el considerar las normas jurídicas como meros "resultantes" de intereses y de factores de poder; pues siempre se plantea la cuestión del orden justo de los intereses. Y formulado todavía de otra manera: Si en el marco del "pluralismo fáctico" resulta imposible "reconocer un sistema de normas completo y comprensible para cada uno, hace falta entonces decidir sobre lo que debe ser justo. O, como dijo Radbruch: "Si nadie puede fijar lo que es justo, entonces alguien tiene que prescribir lo que debe ser justo." Para evitar un decisionismo, habría que "someter las leyes y las instituciones políticas a una crítica ética, teniendo la crítica su criterio sobre todo en la justicia política en tanto que concepto fundamental de una crítica ética del derecho y del estado."

\section{Crítica del estado.}

Sobre todo por parte de los comunitaristas se hace valer hoy que no se puede esperar ninguna solución a los problemas del presente de una "política como actitud de animal de rapiña." El programa de la democracia liberal tiene "poca simpatía con aquel ideal cívico que hace de los hombres seres políticos por naturaleza. Ser ciudadano de un estado es, para ella, —la visión de los liberales-, un rol artificial que el hombre natural asume por prudencia para proteger su ser humano solitario. Pero esto significa que somos políticos para protegernos como seres humanos. Por eso puede sorprender que los comunitaristas convengan ampliamente con los liberales en una estrategia: la crítica del estado, la exigencia de limitar el estado. Los unos le quieren poner límites en nombre de la 
socialidad y del bien común, cuya protección estaría mejor garantizada por la familia y los grupos, y los otros en nombre de la libertad del individuo.

Después del final de la metafísica de la "razón sustancial" esta estrategia resulta peligrosa. Tanto comunitaristas como liberales desconocen que precisamente el "pluralismo fáctico" obliga a reflexionar de nuevo sobre la conexión entre libertad, derecho y estado. Es cierto que la globalización de la economía neoliberal individualista está vinculada a una ideología de una nueva cultura en que las culturas se encuentran, las historias se entrecruzan y los territorios se sobreponen. Es en esta nueva cultura donde los derechos humanos encuentran su lugar. Con los derechos humanos se convierte en algo concreto y global lo que los filósofos llaman el "ser-en-el-mundo" de los hombres. Con la generalidad universal de los derechos humanos nos encontramos realmente en el mundo. Este "mundo" no es ya el estado nacional, como tampoco la economía nacional. Por otra parte, bajo las condiciones del pluralismo, también ha llegado a su fin cualquier centralismo político, sea de proveniencia estalinista o neoliberal.

Pluralismo y derechos humanos han establecido una nueva unión. Parte de esta unión o relación es, por un lado, el fin de la estatalidad nacional, y por otro, el redescubrimiento de identidades culturales regionales y de autonomía local como base de nuestra ciudadanía en el mundo. Dicho de otro modo: la unificación de los seres humanos en la idea de la justicia y del derecho va acompañada de la liberación para aquella diferencia cultural que consiste en el reconocimiento del otro y de mí mismo y que posibilita así la identidad. El sujeto de los derechos humanos no es el "hombre en general" hipotético y abstracto sino la persona en una cultura jurídica.

¿Qué significa todo esto para la cuestión de las funciones y límites del estado? Significa que hay que liberarse de todas las funciones estatales y no esenciales, y fortalecer al estado en sus tareas esenciales. No esenciales son las funciones que el estado ha derivado de la ontología de la nación, de la ideología de la raza y de la prioridad de intereses económicos particulares; esenciales son las funciones que le corresponden al estado constitucional como órgano del derecho en interés de la libertad personal y la dignidad. De esto se sigue que el grito por "menos estado" no es a priori la voz de la emancipación. Tanto en la concepción estalinista como en la neoliberal lleva la limitación de las funciones del estado a la eliminación del espacio público y a la autorización de intereses que en sociedades pluralistas no tienen ninguna justificación para tener privilegios. La crítica desligitimadora del estado va acompañada frecuentemente de una legitimación del terror de lo privado.

La globalización de una forma dominante de particularidad y privacidad no es ya ninguna visión utópica —su nombre es "capitalismo"-. En estas condiciones ¿qué significa el decir "adiós al estado" reclamado en nombre de la libertad?. 
"Con el estado social, económico y ecológico, por una parte, y los regímenes transnacionales, internacionales y supranacionales, por otra; se nombran la metamorfosis más importantes por medio de las cuales el estado moderno reacciona a las situaciones generadas por el capitalismo. La cuestión que no se ha aclarado suficientemente es la de saber si se trata de una metamorfosis en la que sigue siendo reconocible el plano de construcción, el modelo, a través de todas las transformaciones de la figura; o de una metamorfosis que significa descenso, degradación. ¿No se podría pensar que el capitalismo moderno representa un tipo nuevo de orden social en la historia mundial cuya expansión a la larga va a costa de la estatalidad?"

Stefan Brueuer señala que la "suposición de una incompatibilidad entre capitalismo y estado" ya se encuentra en $M$. Weber quien, sin embargo, veía "no al capitalismo sino al estado como triunfador en el conflicto de las configuraciones del orden". "Si hoy... se inicia el final del capitalismo organizado, esto es, del tránsito al "disorganized capitalism", de lo que se trata realmente "no es tanto de una nueva época en la historia del capitalismo, como de una emergencia más clara de su esencia... Mientras que el estado moderno como estado de derecho y estado constitucional surgió precisamente de un movimiento de reacción contra el caos, e intenta canalizarlo de forma duradera mediante la creación de una constitución pactada, el capitalismo es un orden que se produce por el caos o también un caos que se regula a sí mismo — con el alto precio conocido para los perdedores-.

Son muchos los indicios que hablan a favor de que en el conflicto entre estos dos tipos de orden el último es el determinante y que cada vez le impone al estado nuevos retrocesos."

Detengámonos un momento en las controversias sobre del estado. Definiciones como aquella de Max Weber en la que se nos dice que el estado es "una relación de dominio de hombres sobre hombres apoyada en el instrumento del poder legítimo", se orientan demasiado unilateralmente en la característica del poder, como para que puedan comprender el estado de derecho y sus funciones. Aceptable podría ser, aunque no es suficiente, la determinación general de que con "estado" se designa un poder jurídicamente ordenado, soberano y político, territorialmente limitado, cuya finalidad y meta es la de regular de manera duradera la convivencia humana.

En la concepción moderna del estado - en su tendencia - late una antropología escéptica. Ya Jean Bodin en sus Les six livres de la république ( $\left.{ }^{2} 1583\right)$ que debían fundamentar una concepción orientada en la "razón" y en la "felicidad de los ciudadanos" se proponía "seguir las reglas de la política práctica en lo posible", y no un ideal utópico. Bodin sabía que "aquellos que son de una opinión en la definición del bien más alto, no siempre están de acuerdo en que un hombre bueno y un buen ciudadano así como la felicidad de cada uno y la 
del estado coincidan". Cuando más tarde Kant en su Metaphysik der Sitten quiere entender el estado como "unión de una cantidad de hombres bajo leyes jurídicas" (x45), así vemos aquí también la idea de que los hombres están hechos de "madera torcida" y que primeramente deben convertirse en ciudadano del estado de derecho. Al mismo tiempo el concepto moderno de la ley jurídica no es éticamente neutral; contiene la idea de la justicia que limita al estado. Con el concepto de estado está ligada inmediatamente la cuestión por sus fines moralmente legitimados y por los limites de su poder: el estado no tiene ninguna estabilidad ontológicamente garantizada, sino que corre peligro constantemente de perder su legitimidad cuando los ciudadanos no lo reconozcan ya como forma de su "mancomunidad".

En la modernidad el estado está expuesto fundamentalmente al conflicto de las interpretaciones. Su legitimación se funda en el supuesto de que la convivencia humana -en principio no armónica sino conflictual- necesita de un medio de coerción por razones de orden. El rechazo del poder estatal se fundamente en el supuesto a priori de una socialidad humana que hace superfluo al estado, o en el supuesto de que el estado no puede cumplir más que funciones de poder.

\section{Estado y Derecho.}

No se habla del estado sin hablar del derecho. La situación es paradójica. En la modernidad la prevalencia de la subjetividad y de los derechos individuales motivó colisiones de intereses y por ello una positivización jurídica de las relaciones de vida humanas que antes pasaban por estar reguladas por la conformidad en la moral y eticidad. La paradójica se puede presentar en una fórmula simple: Cuanto más libertad, tanto más derecho; cuanto más derecho, tanto más estado; cuando más estado, tanto menos libertad; cuanto menos libertad, tanto mayor la necesidad del derecho — de estado etc.

La idea de los derechos fundamentales y de los derechos humanos que le corresponden a cada individuo por "naturaleza", es decir, antes de la positivización por el estado, nació de la necesidad de asegurar la libertad por el derecho - frente a la tutela o la opresión estatal. Sin embargo la realización de todo derecho se pone en manos del estado como institución de regulación jurídica. El "pluralismo fáctico" es otra vez el que plantea nuevos problemas para la relación entre derecho y estado. Reivindicaciones de una sola fundamentación axiológica material de normas jurídicas son tan poco justificables como la afirmación de una sola verdad. El derecho positivo tiene por esto límites estrechos: 1 . El límite que se muestra en la cuestión de que es lo que es necesario regular en general; y 2. El límite que resulta del carácter ampliamente formal de la constitución como "norma fundamental". 
Las normas de derecho fundamental de constituciones democráticas fundamentan un sistema jurídico determinado en su contenido, pero no se fija que "es lo que se debe en base de las normas de derecho fundamental". "La razón de esto no radica solamente en la apertura semántica y estructural de las definiciones de derecho fundamental sino esencialmente también en el carácter de principio de las normas de derecho fundamental. Su carácter de principio implica la necesidad de ponderación. El procedimiento de la ponderación es ciertamente... un procedimiento racional, pero no es ningún procedimiento que lleve en todo caso a exactamente una solución... La apertura de la ponderación... lleva a una apertura del sistema jurídico determinado en su contenido por las normas de derecho fundamental". Además significa la "validez de las normas de derecho fundamental"... que el sistema jurídico es un sistema abierto frente a la moral".

Como en la sociedad es prácticamente imposible no tener que decidir y renunciar a la normatización, el problema de una relación entre estado y derecho, que tiene su criterio en la justicia, parece insolucionable. No obstante una tendencia histórica constatable da motivo de esperanza. Me refiero al evidente cambio de paradigma consistente en el pasar de un pensar desde el estado a un pensar desde la constitución. Sobre todo en el concepto del estado social, que se ha convertido en un estado que "planea, distribuye, configura y hace posible tanto la vida individual como social, se muestra una liberación de la hasta ahora existente "fijación estatal". La "orientación en la constitución referida al estado y a la sociedad así como en la "democracia de "forma de vida" fortalecen esta tendencia. De acuerdo con esto la democracia no puede ya ser entendida sólo "como mero principio de organización del estado"; según su idea ella es autodominio de los ciudadanos, y en cuanto tal tiene que envolver toda la sociedad civil. La democracia es por eso "el principio primariamente determinante del orden constitucional".

Característico del cambio en la cultura política y jurídica es por otra parte una nueva actitud frente a la positividad del derecho: $\mathrm{Si}$ en la sociedad civil dominaron desde el siglo XVII concepciones, en las que el derecho como derecho dado no necesitaba ser fundamentado racionalmente y reivindicaba su validez a partir de su inmutabilidad, hoy son conscientes en cambio de que el derecho es derecho positivo y "positivizado". Quien concede esto, pide una fundamentación y parte de la constante mutabilidad del derecho. La crítica del derecho abre nuevos caminos en base a la idea de que no todo el derecho cumple de la misma mánera estas funciones:

- Fundamentar el estado desde la constitución (y no al revés),

- Fundamentar racionalmente la autonomía del derecho frente al poder político,

- Corresponder a las exigencias de regulación e integración de una sociedad pluralista, y 
- Fundamentar y desarrollar la democracia como forma de configuración de todos los sectores del estado social.

Pero con esto no se ha decidido todavía qué es y qué deba ser la democracia. También los modelos políticos son como interpretaciones "propias" (obstinadas) contextos de culturas. A esto corresponde que conceptos de democracia aceptables tienen que ser formales; son esencialmente procedurales. Pero, haciendo caso omiso de esta formalidad, hay algo que está indisolublemente ligado al concepto de democracia: La forma de poder en la que los ciudadanos mismos y su estado "se ponen en el derecho", es expresión de la interdependencia entre el estado y la sociedad. Por eso "no se puede realizar plenamente el principio de la democracia en el sector estatal sin democratizar la sociedad". Son los derechos fundamentales y los principios de la estatalidad social y jurídica, y de la democracia, fundados en ellos, los que "(obligan) a la legislación, al poder ejecutivo y a la jurisprudencia a encargarse de la realización de las decisiones fundamentales también en el campo de la sociedad".

El pluralismo de las libertades y el orden de un derecho regulador de las libertades están en una relación de complementariedad: El derecho domestica el estado-poder; el derecho se realiza en el estado-constitucional bajo la condición de estar comprometido con la justicia política y social.

La democracia moderna exige principios de justicia, de igualdad y de universalidad del derecho que sean formales y neutrales frente a las interpretaciones del mundo. Estos principios pueden reclamar por esos su validez como derecho positivo formal. $Y$ esto significa, hablando con Hans Kelsen, "la renuncia a la costumbre tradicional de defender en nombre de una ciencia del derecho, es decir, recurriendo a una instancia objetiva, exigencias políticas que sólo pueden tener un carácter sumamente subjetivo, aún cuando se presenten con la mejor fe como ideal de una religión, de una nación o de una clase".

\section{Funciones del estado}

Las transformaciones en el derecho positivo pueden ser leídas por lo general como respuestas a cuestiones que se plantean a partir de experiencias de injusticia. Una de las respuestas que se dan en Europa después de las experiencias del fascismo, pero también en razón de deficiencias jurídicas en los estados del llamado socialismo real, consiste en que "no solamente el estado es el enemigo potencial de los derechos fundamentales sino que amenaza también el terror del derecho fundamental desde los ciudadanos como detentores del derecho fundamental, esto es, desde nosotros". Una conclusión se ve en el concepto de la "democracia militante": esto significa una "fijación de valores por la constitución que en el proceso democrático de formación de la voluntad no deben ser violados". 
Derechos fundamentales son derechos directamente vigentes; son vinculantes para la legislación, el poder ejecutivo y la jurisprudencia. Para proteger de todo peligro la vinculación jurídica a través de los derechos fundamentales, es decir la obligación de todo poder estatal a la protección de la "dignidad del hombre" y al respeto de "los derechos humanos como fundamento de toda comunidad humana, de la paz y de la justicia en el mundo", las constituciones democráticas conocen el principio de la obstrucción del contenido esencial ("Wesensgehaltssperre"): ningún derecho fundamental debe ser violado en su contenido esencial.

Supuesto esto, se considera a los estados como legitimados para ejercer funciones de protección y de control de los ciudadanos, pero también de autoprotección frente a los ciudadanos: Así por ejemplo está la familia bajo la protección del orden estatal, y la obligación de los padres a educar a los hijos es controlada por el estado. Las constituciones democráticas conceden también protección ante la situación de apátrida, aunque a precio de que la garantía de derechos iguales está conectada a una ciudadanía estatal-nacional. El estado es responsable frente a los ciudadanos en caso de violación de sus obligaciones oficiales, y debe posibilitarle a los ciudadanos afectados el recurso a la vía legal. Por otra parte la protección del estado frente a los ciudadanos también tiene un gran peso en las democracias ("protección del estado").

La ambigüedad del estado se funda en la problemática de la diferencia, y a veces de la contradicción entre el derecho a la libertad y la garantía de la libertad: "Los individuos necesitan el estado para poder gozar sus derechos y fomentar sus intereses. El estado protege la libertad de cada uno y la limita al mismo tiempo de tal manera que no perjudique la libertad igual de cada uno de los demás". Por otra parte: "En la medida en que el estado está equipado con poder y medios de coerción para cumplir esta tarea, este poder del estado tiene a su vez que ser limitado de manera que no amenace la libertad de los individuos." Dicho en fórmula apretada: "la condición jurídica que garantiza la libertad no se hace por sí misma, sino que necesita también de la instancia que, dado el caso, establece el derecho, lo promulga concretamente y que asegura su observancia frente a los resistentes. El derecho exige el estado como institución de su propia garantía."

\section{La justificación del estado mediante las funciones jurídicas y sociales.}

Una concepción realista de los derechos fundamentales y los derechos humanos no puede ignorar que la universalidad y la validez de estos derechos —si no quieren ser conjurados sólo de manera declamatoria - necesitan de la realización del derecho por el estado, al menos por un espacio de tiempo previsible. Sólo unos derechos humanos positivados pueden asegurar la libertad y la justicia. Aquí hay que tener en cuenta como un problema la representación de las contradicciones sociales de intereses en el marco de la democracia fundamental. 
Bajo las condiciones del capitalismo la capacidad de función de una democracia política, de la que debe esperarse la protección de los derechos humanos, depende de su desarrollo en el sentido de una democracia social. Sólo entonces -en esto sigo la Staatslehre (publicada en 1934) de Hermann Heller- puede el poder del estado ser poder jurídico; esto quiere decir no solamente actuar técnico jurídicamente como poder, sino valer como autoridad legitimada y comprometida moralmente con la voluntad... Los inmensos derechos del estado son legítimos no porque asegure un orden social, sino sólo porque persigue un orden justo. Sólo a través de la relación de la función estatal con la función jurídica es posible la sanción del estado... Sin una separación entre derecho e injusticia no es posible una justificación del estado. Esta separación se puede llevar a cabo sólo sobre la base de un criterio jurídico que debe de suponerse como estando por encima del estado y su derecho positivo". Otra vez H. Heller: "Que el estado sólo puede ser sancionado en su calidad de organización para la garantía jurídica, quiere más bien decir que puede ser justificado sólo en cuanto que sirve a la aplicación y a la realización de principios jurídicos éticos.".

\section{Los derechos humanos como presupuesto de la legitimidad estatal e interestatal.}

En su "tercera generación" los derechos humanos positivados son tan concretos que no tenemos ya necesidad de las declamaciones vacías de una ideología de los derechos humanos. Al mismo tiempo han permanecido suficientemente generales como para asegurar su universalidad y poder responsabilizar a los estados de distintas culturas políticas y jurídicas. De esta suerte nombra por ejemplo el "International Convenant on Civil and Political Rights" (23.3.1976) como principios, "de acuerdo con los principios proclamados en la carta de las naciones unidas, (el) reconocimiento de la inherente dignidad y de los derechos iguales e inalienables de todos los miembros de la familia humana es la base de la libertad, la justicia y la paz en el mundo; reconociendo que estos derechos se derivan de la inherente dignidad de la persona humana..."

Para los derechos humanos vale también lo que hay que decir de los derechos fundamentales: El reclamo de derechos fundamentales por una parte y el orden estatal por otra se condicionan mutuamente en constelaciones históricas cambiantes: "El derecho es derecho históricamente devenido y sin su historia no se puede comprender... Los derechos fundamentales son, como parte del derecho estatal y constitucional, derechos políticos y están sometidos al cambio de los órganos políticos. Al mismo tiempo los derechos fundamentales son también una respuesta a la cuestión fundamental permanente por la relación entre libertad individual y orden político".

La ampliación, concretización y positivización legal de los derechos humanos y el derecho internacional como derecho del ciudadano del mundo, sobre- 
puesto a los estados nacionales, conforman hoy las condiciones fundamentales de la universalidad y la reciprocidad de la concesión de los derechos fundamentales entre los ciudadanos. Con los derechos humanos en su figura positivizada ha ganado realidad una perspectiva antes utópica; los derechos humanos fundamentan así el presupuesto de una cultura jurídica cosmo-política es la forma de la libertad que los ciudadanos y ciudadanas deben concederse y garantizarse mútuamente y universalmente. No es pues "el estado" o "la comunidad", los que conceden derechos y libertades a los ciudadanos/as sino que los ciudadanos/as son al mismo tiempo autores y destinatarios de los derechos a la libertad."

Como pueden fundarse estos derechos a la libertad, es algo que depende esencialmente de la respuesta a la cuestión siguiente: ¿Hay razones jurídicas pre-positivas que, bajo las condiciones del pluralismo de las imágenes del mundo individualizadas, así como actitudes axiológicas y concepciones jurídicas que puedan reclamar una validez universal? La otra cuestión de sí la constitución como norma fundamental tiene su criterio de juicio en los derechos humanos, no se puede resolver sin la respuesta a la primera. Mi respuesta es esta:

Las fundamentaciones de normas y la explicación de las leyes desde el derecho, más exactamente desde la "norma fundamental" que se llama constitución, no son posibles sin definiciones materiales mínimas.

El contenido material de la "norma fundamental" consiste en el cuerpo de los derechos humanos.

Se trata de una fundamentación de un argumento que es en definitiva iusnaturalista y que Arndt lo formuló así: De todos los conceptos que se emplean en este contexto el concepto de los derechos humanos es todavía el más claro: designa los derechos que deben ser comunes a todos los hombres en virtud de su ser humano e independientemente de su edad, del color de su piel, de su sexo, de su ciudadanía o de su procedencia social —derechos que además no son dados o concedidos por el estado sino que le corresponde a aquel que lleva un rostro humano por naturaleza en virtud de su nacimiento, derechos que por su carácter original e inalienable no pueden ser denegados ni en principio tampoco retirados, y a los que tampoco nadie (voluntaria o involuntariamente) puede renunciar."

El problema de la universalidad está unido al problema de la fundamentación. Los estados tienen que tener una razón para poder reconocer que las reglas vinculantes transnacionales: 1 . No contradigan su sistema de normas intraestatal y 2. Ajustar el derecho intraestatal a las normas convenidas, en caso de que entren en contradicción con los derechos humanos.

No veo otra solución al problema que la de recorrer el camino de la fundamentación que I. Maus en su interpretación de la función regulativa del derecho natural describió así: La abstracción consciente (de las teorías iusnaturalistas) de 
todas las condiciones de constitución de los sujetos, la reducción atomística de los individuos a una "naturaleza", que reclama prioridad lógica y normativa frente a las organizaciones estatales tenía por fin el atribuirle a esta naturaleza del hombre derechos que eran anteriores a las instituciones políticas. Precisamente las abstracciones de esta argumentación iusnaturalista sirvieron a la calificación de todos los derechos a la libertad como derechos preestatales.

Es precisamente esta abstracción de la idea regulativa del derecho natural al que bajo las condiciones del "pluralismo fáctico" ofrece dos presupuestos esenciales para un derecho a los derechos humanos universal y que al mismo tiempo respete la diferencia de las culturas. Por una parte permite el derecho natural así entendido la mediación entre la universalidad jurídica cosmopolita y diferentes positivizaciones interestatales de los derechos fundamentales que tengan en cuenta las culturas jurídicas históricas. Por otra parte se puede legitimar sobre esta base una reivindicación que, de otra forma, podría conducir al relativismo e incluso al etnopluralismo. Esta reivindicación reza: "El derecho internacional a los derechos humanos tiene que hacer responsables a los estados para que implementen los ideales axiológicos de sus propias civilizaciones, pero no aquellos que les son extraños." El conflicto de las interpretaciones no queda ciertamente resuelto con esto; pero tenemos un criterio para discernir entre buenas y malas versiones del derecho, del estado y de los derechos humanos. 